\title{
What Caused a Geriatric Gait in a Homebound Adolescent?
}

\author{
Deeksha Borkar, MD' - Tara Holm, MD² - Jonathan Strutt, $\mathrm{MD}^{3}$
}
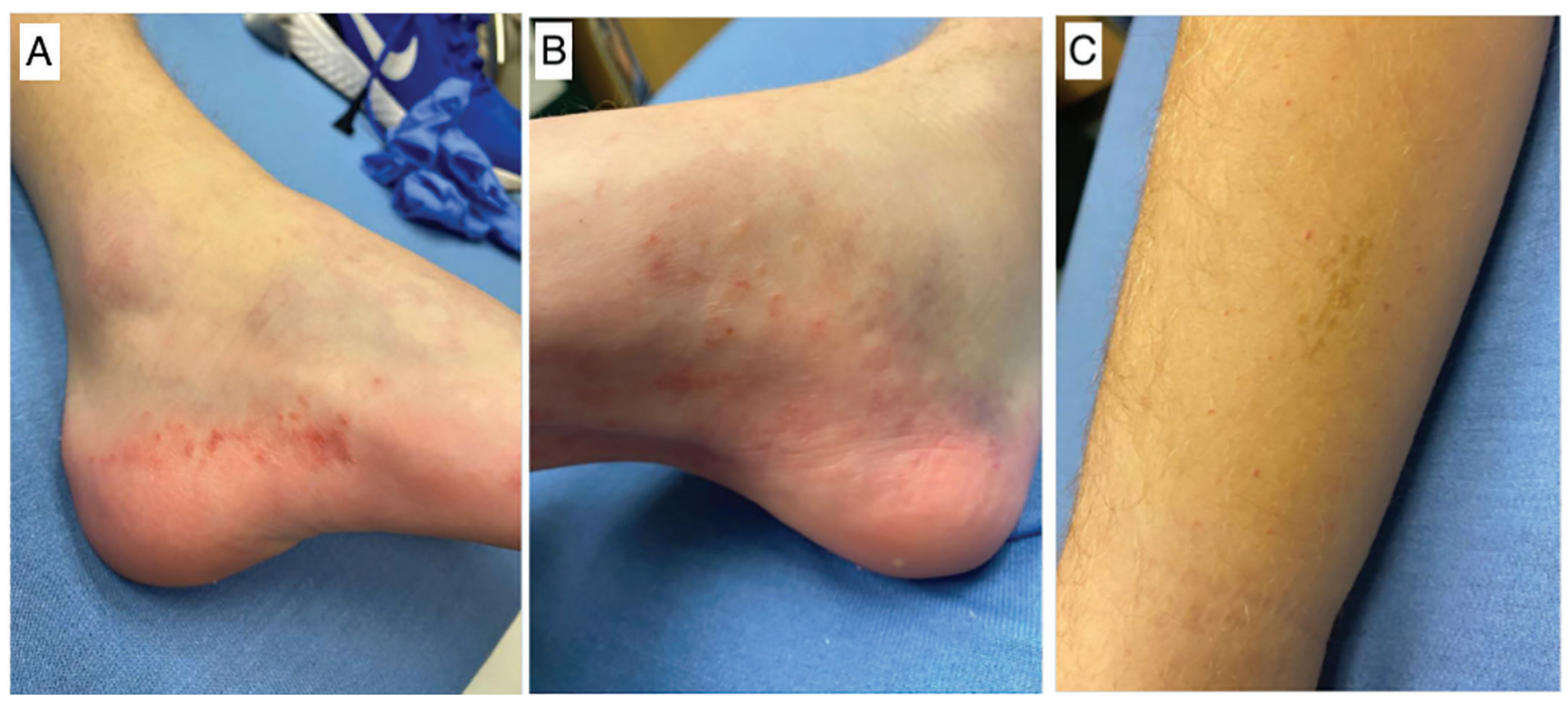

Figure 1. Perifollicular hyperkeratosis and ecchymosis was seen on the medial aspect of the right foot (A), left foot (B), and right shin (C).

An 11-year-old boy with a medical history significant for autism spectrum disorder and attention-deficit/hyperactivity disor$\operatorname{der}(\mathrm{ADHD})$ presented to the emergency department (ED) with a 1-month history of progressive pain and swelling of the right lower extremity. He discloses a history of right foot trauma at an indoor

\section{AFFILIATIONS:}

'Department of Pediatrics, University of Minnesota Medical School, Minneapolis, Minnesota

${ }^{2}$ Department of Radiology, Division of Pediatric Radiology, University of Minnesota Medical School, Minneapolis, Minnesota

${ }^{3}$ Department of Pediatrics, Division of Pediatric Emergency Medicine, University of Minnesota Medical School, Minneapolis, Minnesota

\section{CITATION:}

Borkar D, Holm T, Strutt J. What caused a geriatric gait in a homebound adolescent? Consultant. Published online May 24, 2021. doi:10.25270/con.2021.05.00008

Received January 1, 2021. Accepted February 19, 2021.

\section{DISCLOSURES:}

The authors report no relevant financial relationships.

\section{CORRESPONDENCE:}

Deeksha Borkar, MD, University of Minnesota Medical School, 2450 Riverside Ave, Room M136, Minneapolis, MN 55454 (borka015@umn.edu)

gymnasium around the time of symptom onset with predominance of pain and swelling over the right calf, ankle, and midfoot. He denied fever, chills, nausea, vomiting, chest pain, shortness of breath, abdominal pain, and problems with bowel or bladder continence. His immunizations were up to date, and he had no history of travel or sick contacts before development of symptoms. He was taking methylphenidate and dexmethylphenidate for ADHD.

His most recent visit with his primary care provider was 2 weeks before presenting to the ED. At that visit, his parents had discussed their concerns that he may have lost muscle mass from spending too much time in his room playing video games during the summer. They had also reported that he "walked like an 80-yearold man" and had described feeling weak. 


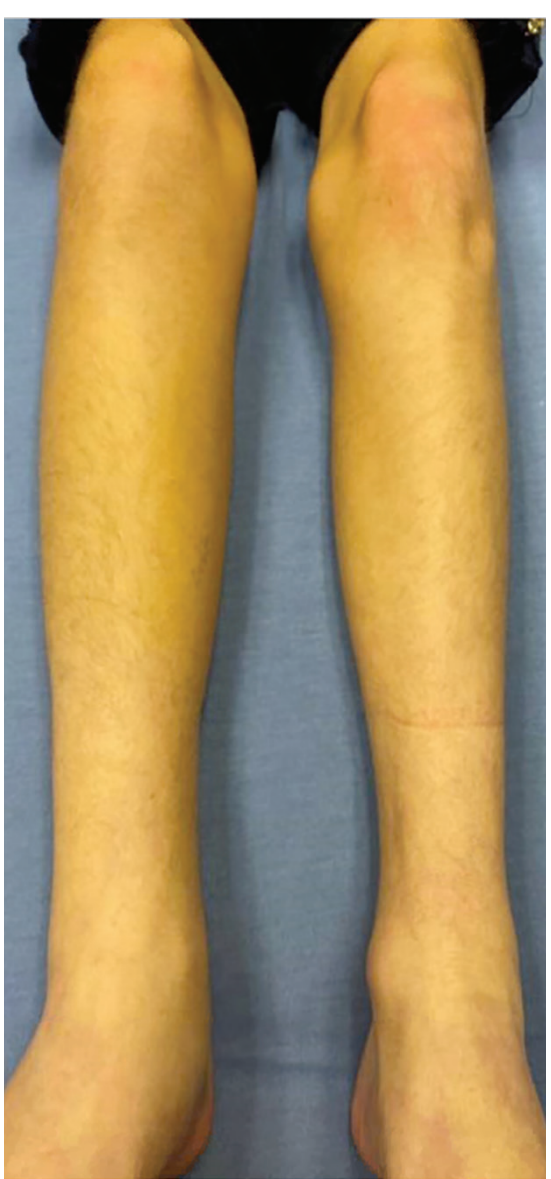

Figure 2. Bilateral lower extremities demonstrating right knee and lower leg swelling with distinct differences in size.

On further discussion, the patient had revealed that his diet was consistently limited to eating only pancakes and eggs for breakfast, skipping lunch, and sometimes eating popcorn as an evening meal/snack, without any dietary or vitamin supplementation.

\section{Physical examination}

The patient was thin with vital signs in the normal limits. His examination was notable for pale skin with perifollicular hyperkeratotic papules noted over bilateral feet and shins. He had ecchymosis over the dorsal aspect of his right foot (Figure 1). A musculoskeletal examination was notable for right knee prepatellar effusion without warmth, erythema, or tenderness to palpation. Right lower leg swelling was noted with multiple areas of ecchymosis, tense but compressible muscle tissue, and tenderness to palpation. There was associated right ankle swelling with edema and ecchymosis of the right midfoot as well (Figures 1 and 2). Decreased active and passive range of motion of the right ankle was also present.

\section{Diagnostic testing}

Initial laboratory findings were notable for anemia with a hemoglobin level of $9.9 \mathrm{~g} / \mathrm{dL}$, mild leukopenia with a white blood cell count of $3.9 \times 109 / L$, and mild hypocalcemia with a serum calcium concentration level of $8.3 \mathrm{mg} / \mathrm{dL}$. Laboratory findings of iron deficiency anemia were noted, with a total iron level of $20 \mathrm{ug} / \mathrm{dL}$, iron binding capacity of $340 \mathrm{ug} / \mathrm{dL}$, and a low iron saturation index of $6 \%$. Total creatine kinase, uric acid, ferritin, and lactate dehydrogenase levels were within normal limits. Magnetic resonance imaging (MRI) studies of the bilateral lower extremities revealed long bone metaphyseal marrow signal abnormalities, bilateral proximal tibial periostitis (right greater than left), right-sided myositis, and bilateral subcutaneous edema (right greater than left) (Figures 3-5).

\section{At this point, how would you diagnose this boy's condition?}
A. Immune thrombocytopenic purpura
B. Vitamin D deficiency
C. Hypersensitivity vasculitis
D. Inflammatory bone disease
E. Vitamin C deficiency

\section{Answer: E. Vitamin C deficiency}

A preliminary diagnosis of nutritional deficiency of vitamin C (scurvy) was made through the patient's dietary history and characteristic dermatological and imaging findings (Figures 3-5). A conclusive diagnosis was made after a serum vitamin $\mathrm{C}$ level was obtained after imaging and was noted to be low, at less than $0.09 \mathrm{mg} / \mathrm{dL}$ (reference range, 0.4-2.0 $\mathrm{mg} / \mathrm{dL}$ ) with laboratory evidence of iron deficiency anemia.

\section{Discussion}

Scurvy, as a nutritional deficiency, is a rare phenomenon in developed countries.' According to the National Health and Nutrition Examination Survey (NHANES) III, between 1988 and 1994, approximately $13 \%$ to $23 \%$ of the population of the United States was deficient in vitamin $\mathrm{C}^{2}$ This statistic improved in the most recent NHANES survey between 2003 and 2004, where the prevalence of vitamin C deficiency was noted to be $8.4 \%$, comprising $10 \%$ of men and $6.9 \%$ of women. ${ }^{3,4}$ However, vitamin C, or ascorbic acid, deficiency is noted to be common among elderly patients and those lacking access to fresh fruits and vegetables. ${ }^{5}$

Although scurvy is rare, the most classical presentation of scurvy is gingival hyperplasia and bleeding from the gums. ${ }^{6}$ Pathognomonic dermatological findings include perifollicular hemorrhages, follicular hyperkeratosis, corkscrew hair, and xerosis. $^{7,8}$ In our case, the patient presented with progressive leg swelling and pain for over a month without the classical findings or history of bleeding gums while brushing his teeth or gingival hyperplasia on physical examination. He did have follicular hyperkeratosis, however.

In the pediatric population, bone disease is often noted as a radiographic finding. Osteological MRI findings of scurvy as described in the literature reveal areas of subperiosteal hemorrhage within the bones, periosteal changes, low marrow signal intensity on T1-weighted images, and corresponding, high marrow signal intensity on T2-weighted images. ${ }^{9-12}$ With the exception of subperiosteal hemorrhage, our patient had all of these findings.

Vitamin $\mathrm{C}$ is a water-soluble vitamin that is absorbed from the gastrointestinal tract. The recommended dietary allowance for vitamin $\mathrm{C}$ in the pediatric population ranges from $15 \mathrm{mg}$ to $90 \mathrm{mg}$ daily depending on the age group of children from 0 to 18 years of age..$^{13,14}$ About $70 \%$ to $90 \%$ of consumed vitamin $C$ is absorbed when the intake is moderate and in the range of 30 to $180 \mathrm{mg}$ daily. ${ }^{14}$ Vitamin $\mathrm{C}$ is 


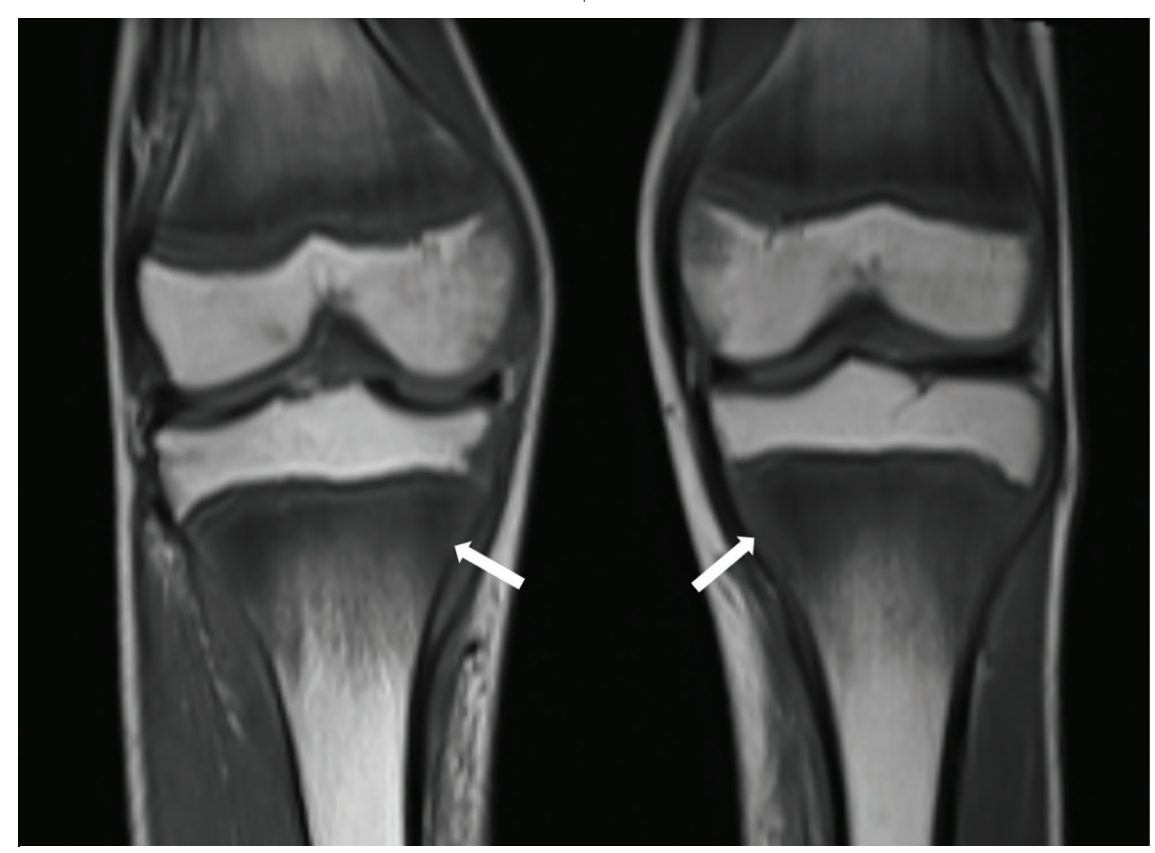

Figure 3. T1-weighted coronal MRI scans of both knees demonstrated abnormal dark metaphyseal bone marrow signal, isointense to skeletal muscle in the proximal tibia and distal femur bilaterally.

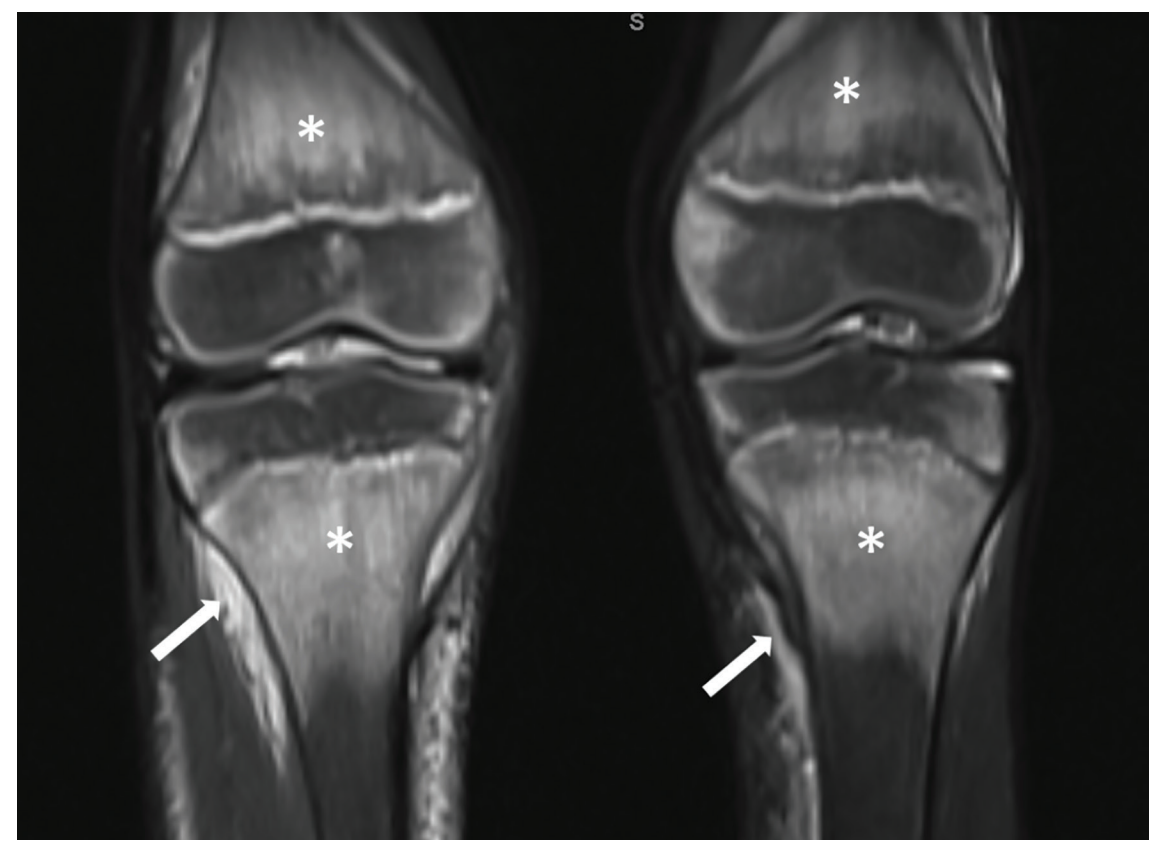

Figure 4. Coronal STIR sequence scans demonstrated abnormal high metaphyseal marrow signal and high signal periostitis in the tibial metaphysis, greater on the right.

important for the synthesis of collagen, which is a crucial component of connective tissue development.15,16 It also plays an integral role in wound healing. Defi- ciency of dietary vitamin $\mathrm{C}$ decreases the absorption of nonheme iron and folic acid, resulting in iron deficiency anemia.10 In our case, the patient's dietary history and iron deficiency anemia indicated vitamin $\mathrm{C}$ deficiency. The diagnosis of scurvy was made clinically and then confirmed by measuring his level of serum vitamin $\mathrm{C}$.

Treatment of scurvy is directed at initiation of daily vitamin $C$ supplementation in addition to vitamin C-rich foods, including citrus fruits (ie, lemons, limes, oranges) and vegetables. ${ }^{17}$ Treatment doses of vitamin $\mathrm{C}$ in infants and children range from 100 to $300 \mathrm{mg}$ daily for a duration of 4 weeks. ${ }^{18,19}$ Considering that iron deficiency anemia secondary to scurvy and folate deficiency is refractory to iron treatment, ${ }^{20,21}$ our patient was started on iron, folate, and vitamin $\mathrm{C}$ supplements. In multiple cases, MRI findings of scurvy have been noted to resolve completely on repeat imaging studies obtained several weeks later. ${ }^{8,9,22-24}$

\section{Patient outcome}

Our patient presented with the musculoskeletal findings of vitamin $\mathrm{C}$ deficiency as opposed to the classical presentation of bleeding gums and delayed wound healing. ${ }^{6} \mathrm{~A}$ detailed discussion regarding nutrition and the importance of a balanced diet was conducted with the patient and his family. As our patient was hemodynamically stable, he was discharged home from the ED with prescriptions for multivitamins, cholecalciferol, and iron and vitamin $\mathrm{C}$ supplements. We recommended outpatient follow-up with a pediatrician within 1 week of ED discharge for repeat serum vitamin $C$ level testing, as well as ongoing nutritional counseling and monitoring.

At the follow-up visit with his pediatrician, an improvement of his right lower leg swelling was noted, along with resolution of his generalized weakness and rash. Repeat laboratory testing was notable for a normal vitamin C level of $1.46 \mathrm{mg} /$ $\mathrm{dL}$ after 12 days of treatment. Iron studies showed improvement, with increases in his hemoglobin level to $11.8 \mathrm{~g} / \mathrm{dL}$, total iron level to $48 \mathrm{ug} / \mathrm{dL}$, and iron saturation index to $13 \%$. The patient has adhered to the treatment recommendations and has made extensive dietary changes. 


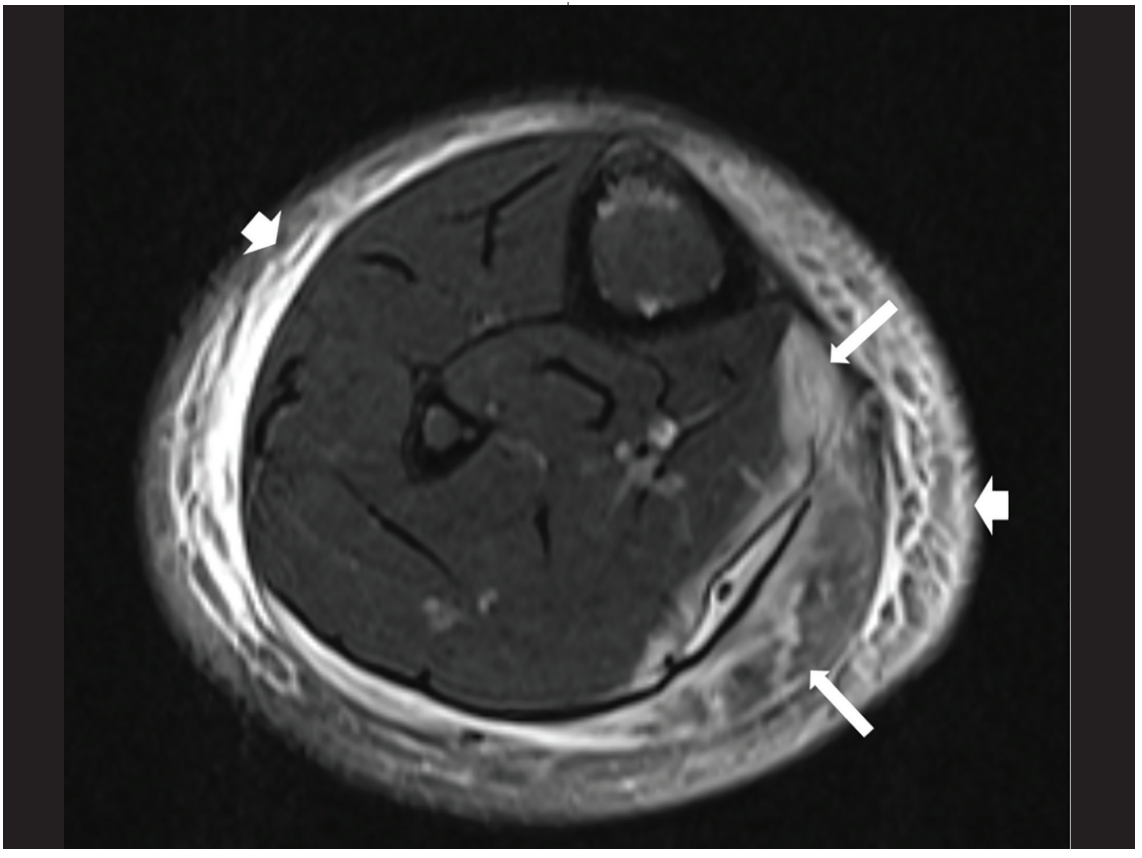

Figure 5. Lower right leg axial T2-weighted scan with fat saturation demonstrated high signal in the subcutaneous tissues and calf musculature (gastrocnemius and soleus muscles) consistent with subcutaneous edema and myositis.

\section{References}

1. Hampl JS, Johnston CS, Mills RA. Scourge of black-leg (scurvy) on the Mormon trail. Nutrition. 2001;17(5):416-418. https://doi. org/10.1016/s0899-9007(01)00512-3

2. Hampl JS, Taylor CA, Johnston CS. Vitamin $C$ deficiency and depletion in the United States: the Third National Health and Nutrition Examination Survey, 1988 to 1994. Am J Public Health. 2004;94(5):870-875. https:// doi.org/10.2105/ajph.94.5.870

3. Schleicher RL, Carroll MD, Ford ES, Lacher DA. Serum vitamin $C$ and the prevalence of vitamin $\mathrm{C}$ deficiency in the United States: 2003-2004 National Health and Nutrition Examination Survey (NHANES). Am J Clin Nutr. 2009;90(5):1252-1263. https://doi. org/10.3945/ajcn.2008.27016

4. Rowe S, Carr AC. Global vitamin C status and prevalence of deficiency: a cause for concern? Nutrients. 2020;12(7):2008. https://doi.org/10.3390/nu12072008

5. Velandia B, Centor RM, McConnell V, Shah M. Scurvy is still present in developed countries. J Gen Intern Med. 2008;23(8):12811284. https://doi.org/10.1007/s11606-0080577-1

6. Kittisakmontri K, Swangtrakul N, Padungmaneesub W, Charoenkwan P. Gingival bleeding and bloody dialysate: a case report of scurvy in a child with end-stage renal disease receiving peritoneal dialysis. $J$ Ren Nutr. 2016;26(6):407-411. https://doi.org/10.1053/j. jrn.2016.03.003

7. Weinstein M, Babyn P, Zlotkin S. An orange a day keeps the doctor away: scurvy in the year 2000. Pediatrics. 2001;108(3):E55. https://doi.org/10.1542/peds.108.3.e55

8. Lessing JN, LaMotte ED, Moshiri AS, Mark NM. Perifollicular haemorrhage with corkscrew hair due to scurvy. Postgrad Med J. 2015;91(1082):719-720. https://doi. org/10.1136/postgradmedj-2015-133661

9. Karthiga S, Dubey S, Garber S, Watts R. Scurvy: MRI appearances. Rheumatology (Oxford). 2008;47(7):1109. https://doi. org/10.1093/rheumatology/ken160

10. Hirschmann JV, Raugi GJ. Adult scurvy. J Am Acad Dermatol. 1999;41(6):895-910. https:// doi.org/10.1016/s0190-9622(99)70244-6

11. Golriz F, Donnelly LF, Devaraj S, Krishnamurthy R. Modern American scurvy - experience with vitamin $C$ deficiency at a large children's hospital. Pediatr Radiol. 2017;47(2):214-220. https://doi.org/10.1007/s00247-016-3726-4

12. Gulko E, Collins LK, Murphy RC, Thornhill $\mathrm{BA}$, Taragin BH. MRI findings in pediatric patients with scurvy. Skeletal Radiol. 2015;44(2):291-297. https://doi.org/10.1007/ s00256-014-1962-y
13. Institute of Medicine Panel on Dietary Antioxidants and Related Compounds. Dietary Reference Intakes for Vitamin C, Vitamin E, Selenium, and Carotenoids. National Academies Press; 2000.

14. National Institutes of Health. Vitamin C fact sheet for health professionals. Updated March 26, 2021. Accessed May 12, 2021. https://ods.od.nih.gov/factsheets/VitaminC-HealthProfessional

15. Carr AC, Frei B. Toward a new recommended dietary allowance for vitamin $\mathrm{C}$ based on antioxidant and health effects in humans. Am J Clin Nutr. 1999;69(6):1086-1107. https://doi. org/10.1093/ajcn/69.6.1086

16. Gershoff SN. Vitamin C (ascorbic acid): new roles, new requirements? Nutr Rev. 1993;51(11):313-326. https://doi. org/10.1111/j.1753-4887.1993.tb03757.x

17. Léger D. Scurvy: reemergence of nutritional deficiencies. Can Fam Physician. 2008;54(10):1403-1406. https://www.ncbi. nlm.nih.gov/pmc/articles/PMC2567249/

18. Agarwal A, Shaharyar A, Kumar A, Bhat MS, Mishra M. Scurvy in pediatric age group - a disease often forgotten? J Clin Orthop Trauma. 2015;6(2):101-107. https://doi. org/10.1016/j.jcot.2014.12.003

19. Baradhi KM, Vallabhaneni S, Koya S. Scurvy in 2017 in the USA. Proc (Bayl Univ Med Cent). 2018;31(2):227-228. https://doi.org/10.1 080/08998280.2018.1435115

20. Clark NG, Sheard NF, Kelleher JF. Treatment of iron-deficiency anemia complicated by scurvy and folic acid deficiency. Nutr Rev. 1992;50(5):134-137. https://doi. org/10.1111/j.1753-4887.1992.tb01304.x

21. Conway M, Marcon P, Meinert P, et al. A toddler with treatment-resistant iron deficiency anemia. Pediatrics. 2018;142(1):e20172971. https://doi.org/10.1542/peds.2017-2971

22. Khan N, Furlong-Dillard JM, Buchman RF. Scurvy in an autistic child: early disease on MRI and bone scintigraphy can mimic an infiltrative process. BJR Case Rep. 2015;1(3):20150148. https://doi.org/10.1259/ bjrcr.20150148

23. Choi SW, Park SW, Kwon YS, et al. MR imaging in a child with scurvy: a case report. Korean J Radiol, 2007;8(5):443-447. https:// doi.org/10.3348/kjr.2007.8.5.443

24. Gallizzi R, Valenzise M, Passanisi S, Pajno GB, De Luca F, Zirilli G. Scurvy may occur even in children with no underlying risk factors: a case report. J Med Case Rep. 2020;14:18. https://doi.org/10.1186/s13256020-2341-z 